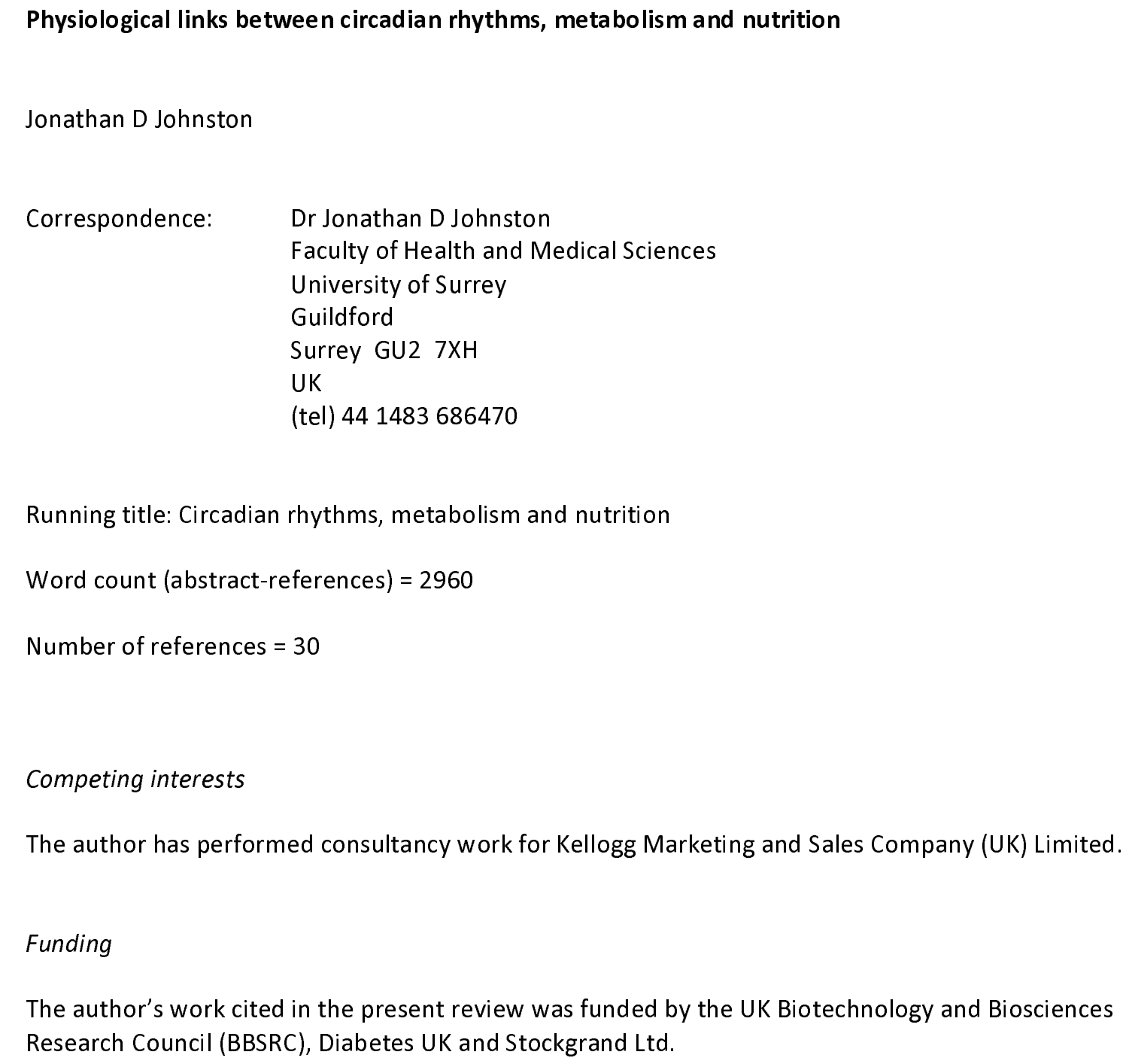




\title{
New Findings
}

- What is the topic of this review?

Discussion of the links between circadian, metabolic and nutritional physiology, with a particular focus on mouse and human studies.

- What advances does it highlight?

Links between circadian biology and metabolism exist from the molecular level through to whole organism physiology. Advances highlighted include: interactions between circadian clock genes/proteins and intracellular metabolic pathways; identification of the function of clocks in specific peripheral tissues; effects of timed feeding; and the variable effect of obesity on rhythms.

\begin{abstract}
Circadian rhythms, metabolism and nutrition are closely inter-linked. A great deal of recent research has not only investigated how aspects of metabolic physiology are driven by circadian clocks, but how these circadian clocks are themselves sensitive to metabolic change. At the cellular level, novel feedback loops have been identified that couple circadian 'clock genes' and their proteins to expression of nuclear receptors, regulation of redox state and other major pathways. Using targeted disruption of circadian clocks, mouse models are providing novel insight into the role of tissuespecific clocks in glucose homeostasis and body weight regulation. The relationship between circadian rhythms and obesity appears complex, with variable alteration of rhythms in obese individuals. However, it is clear from animal studies that the timing and nutritional composition of meals can regulate circadian rhythms, particularly in peripheral tissues. Translation of these findings to human physiology now represents an important goal.
\end{abstract}




\section{Circadian rhythms and the circadian timing system}

Many biological processes, ranging from metabolic pathways to physiology and behaviour, exhibit 24-hour rhythms driven by endogenous circadian clocks. Increased morbidity occurs following prolonged desynchrony of circadian rhythms and the external environment, such as during shift work and chronic jet-lag. Of particular relevance to this symposium, shift workers exhibit greater prevalence of obesity and associated disorders (reviewed in Antunes et al., 2010).

Circadian rhythms in mammals are widespread and regulate most, if not all, of the major physiological systems. These rhythms are generated by a circadian timing system, which consists of a 'master' clock within the suprachiasmatic nuclei (SCN) of the anterior hypothalamus and multiple 'peripheral' clocks located elsewhere within the brain and throughout the body (reviewed in Mohawk et al., 2012). The SCN clock is synchronised to the external light-dark cycle and acts to maintain internal synchrony within the individual. In this way the circadian system is able to maintain an appropriate phase relationship to the external solar day. The mechanisms through which the SCN synchronise peripheral clocks are complex and not yet fully understood. Neuroendocrine pathways are likely to play a key role in this process, as the autonomic nervous system and hormones such as pineal melatonin and adrenal glucocorticoids are under SCN control (reviewed in Mohawk et al., 2012). Through influence on sleep-wake timing the SCN also exert temporal influence over behavioural factors, such as social interaction and feeding time, that can synchronise circadian rhythmicity. Indeed, as described below, animal studies suggest timed feeding is a major regulator of the phasing of peripheral clocks.

\section{Linking circadian rhythms, metabolism and nutrition}

Much work has been conducted in this area of chronobiology over recent years. Animal and cellular studies have clearly demonstrated that rhythms and metabolism are intimately linked across multiple levels of biological organisation. Due to space limitations, this article will only focus on a subset of the available literature.

\section{Molecular and biochemical links}

The molecular mechanisms underpinning mammalian circadian rhythms have been extensively reviewed elsewhere (e.g. Buhr \& Takahashi, 2013). In brief, the dominant molecular model is comprised of a set of interlocking transcriptional-translational feedback loops (TTFL). The primary loop consists of the proteins CLOCK and BMAL1 stimulating transcriptional activity of three Period (Per) and two Cryptochrome (Cry) genes. After appropriate temporal delay caused by posttranslational modifications, the translated PER and CRY proteins then form protein complexes that translocate into the nucleus and inhibit their own transcription via interaction with CLOCK and BMAL1.

In addition to the primary loop, there are many interactions between the above 'clock genes', their resulting proteins and key biochemical pathways regulating intracellular metabolism. These have been reviewed in detail by others (Bass, 2012), but some examples are mentioned here. For instance circadian clock proteins act as transcription factors to drive the rhythmic expression of approximately $50 \%$ of nuclear receptors in key metabolic tissues. In turn, many of these nuclear receptors are able to regulate the expression of clock genes/proteins, thus forming additional 
feedback loops linking the molecular clock to cell metabolism. Other major components of intracellular biochemistry that are reported to regulate clock function include AMPK, NAD and even cAMP (Bass, 2012).

\section{Genetic links}

Long-term changes in key aspects of metabolic physiology, such as glucose homeostasis and energy balance, are closely tied to clock gene structure. One of the predominant mouse models of disrupted circadian rhythms is the 'Clock mutant' mouse, which expresses a dominant negative version of the CLOCK protein. Studies of this mouse found wide-ranging metabolic dysregulation including: enhanced glucose response to insulin challenge and impaired gluconeogenesis (Rudic et al., 2004), obesity and metabolic syndrome (Turek et al., 2005). Subsequent studies of many different 'whole animal' transgenic mice with altered clock gene function have also reported abnormal metabolic phenotypes (reviewed in Bass, 2012). Similar findings have been reported in human genetic studies. Polymorphisms of human clock genes and their associated haplotypes have been associated with multiple metabolic disorders including obesity, metabolic syndrome and type 2 diabetes (e.g. Woon et al., 2007; Scott et al., 2008).

Although the above studies provide clear functional links between clock genes and metabolic activity, they are unable to identify the contribution of individual tissue clocks to the overall phenotype. To address this problem, later animal studies have 'knocked out' BMAL1 in a tissuespecific manner thereby creating localised clock disruption. Loss of BMAL1 in either of the liver, pancreas or skeletal muscle leads to changes in glucose metabolism. Liver-specific clock disruption causes fasting hypoglycaemia and elevated glucose clearance following acute glucose administration (Lamia et al., 2008). Pancreas-specific clock disruption results in hyperglycaemia and lowered glucose tolerance, as a result of reduced insulin secretion (Marcheva et al., 2010). Skeletal musclespecific clock disruption leads to decreased insulin-dependent glucose uptake in skeletal muscles and also altered muscle glucose metabolism (Dyar et al., 2014). By contrast, disruption of the clock in white adipose tissue induces obesity; this is thought to be the result of abnormal PUFA secretion from adipocytes regulating hypothalamic appetite centres and causing increased feeding during the resting phase of the day (Paschos et al., 2012).

\section{Nutritional and dietary links}

The timing of food intake has many physiological consequences (reviewed in Johnston, 2014). The ability of temporally restricted feeding to influence circadian behaviour and physiology has been known for many years. Using rats, it was originally discovered that restriction of food availability to a short period each day results in an intense bout of anticipatory activity directly before the onset of the feeding period. A series of further studies revealed that the timing of this anticipatory activity possesses many of the properties of an endogenous circadian rhythm and so the existence of a food entrainable oscillator (FEO) was proposed (reviewed in Mistlberger, 2009). Intriguingly this FEO persists in SCN-lesioned animals (Mistlberger, 2009) and in mice lacking functional circadian clock genes (Storch \& Weitz, 2009). However its identity is still a matter of debate in the literature.

In humans, there is an established literature describing daily changes in parameters such as glucose homeostasis. In healthy subjects, glucose tolerance lowers throughout the day, leading to the term 'afternoon diabetes'. This phenomenon persists in controlled conditions, indicating that is governed 
by the internal circadian system, and is thought to involve changes in insulin signalling (reviewed in Van Cauter et al., 1997). In addition, lipid metabolism exhibits circadian regulation, with elevated plasma concentration of triacylglycerol (TAG) during the biological night and an elevated postprandial response following a night-time meal compared to the same meal consumed during the day (reviewed in Morgan et al., 2003).

With the recent advances in molecular circadian biology, interest in nutritional links has again become prominent within the field. Animal studies strongly suggest that timed feeding can have beneficial physiological effects, including protection against the obesogenic and metabolic consequences of high-fat diet (Hatori et al., 2012; further discussion in Johnston, 2014). Feeding time is also powerful method of synchronising rodent peripheral clocks. Indeed, when keeping animals in a light-dark cycle, restricting food availability to the time when they would usually be resting/fasting disrupts the internal synchronisation of clocks; the SCN remain synchronised to the light-dark cycle, whereas multiple peripheral clocks re-set to the timing of food availability (Damiola et al., 2000). These peripheral clocks may therefore be important to the functioning of the FEO. In addition, our growing understanding of the role of clocks in individual peripheral tissues is beginning to provide physiological insight to explain temporal differences in post-prandial responses.

\section{Rhythms in obesity}

Differences in daily rhythmicity between lean and obese subjects have been observed in some studies. One of the most widely reported effects of obesity is reduced amplitude of rhythms, both physiological and molecular. However, this is not always the case and there is variation within the literature. A key point to emphasise is that the presence or nature of altered rhythms in obesity depends to a large degree on the specific molecules in question, the tissue(s) studied and other aspects of experimental design.

Daily rhythms exist in the plasma concentration of many hormones. The adipokine leptin exhibits daily rhythms that are likely to be in part driven by endogenous circadian physiology (Shea et al., 2005; Otway et al., 2009). Early reports indicated a decreased amplitude in leptin rhythmicity in obese humans (e.g. Sinha et al., 1996), but this is not reproduced in some later work (e.g. Mantele et al., 2012). Furthermore some endocrine rhythms, such as plasma melatonin, actually exhibit increased amplitude in obese insulin-sensitive men (Mantele et al., 2012).

At the molecular level, reduced amplitude clock gene rhythms have been reported in mice that are obese as a result of either altered genetic background (Ando et al., 2005) or imposition of a high fat diet (Kohsaka et al., 2007). However, there is some inconsistency in the response to diet-induced obesity that may reflect gender of animals studied or other experimental details, such as dietary composition (reviewed in Johnston, 2014). Regarding this last point, it recently been demonstrated that altered rhythms in animals made obese by a high fat diet may reflect acute effects of the dietary intervention rather than any long-term changes in energy balance (Eckel-Mahan et al., 2013).

Few studies have examined daily profiles of gene expression in obese humans. However, in one study using serial sampling of human gluteal subcutaneous fat, no differences in gene expression rhythms were found in lean vs obese individuals (Otway et al., 2011). Limitations of this study include the inability to repeatedly sample visceral adipose depots, which may well have shown altered rhythms. However it does emphasise the point that not all rhythms are altered by obesity and is consistent with the principle that factors other than obesity (e.g. genetic background, acute dietary intervention) may be important regulators other than obesity per se. 


\section{Perspectives}

Research linking daily rhythms and metabolism has gained a great deal of momentum over recent years. Work in model organisms has provided clear and convincing evidence to link these key physiological processes, but many important challenges lie ahead. These include translation to human physiology, functional relationship with pathophysiology, and links with nutritional physiology.

For obvious ethical and practical reasons, access to human tissues obtained in controlled experimental conditions is limited. Subcutaneous fat represents a fairly accessible tissue relevant to the study of obesity. Alternative approaches include viral transfection of cultured human cells (reviewed in Johnston, 2012) or use of blood sampling. Although not frequently considered a 'metabolic' tissue, blood is thought to provide a window into whole body physiology and its molecular rhythms are susceptible to interventions such as timed light exposure, sleep deprivation and sleep timing (Archer et al., 2014). Subcutaneous fat and blood are therefore likely to play a future role in the understanding of circadian metabolism.

An ultimate goal of this work is to apply research data to optimise behaviours, thereby increasing health. This relates both to the general population and to specific groups of individuals (e.g. shift workers) experiencing circadian misalignment and associated metabolic problems. Despite the amount of translational work required, there are already encouraging signs that applying basic models of circadian biology can have a major effect on human obesity. For example, recent studies have provided associations between timing of calorie intake and success in weight loss diets (e.g. Garaulet et al., 2013). 
255

256

257

258

259

260

261

262

263

264

265

266

267

268

269

270

271

272

273

274

\section{References}

Ando H, Yanagihara H, Hayashi Y, Obi Y, Tsuruoka S, Takamura T, Kaneko S \& Fujimura A (2005). Rhythmic messenger ribonucleic acid expression of clock genes and adipocytokines in mouse visceral adipose tissue. Endocrinology 146, 5631-5636.

Antunes LC, Levandovski R, Dantas G, Caumo W \& Hidalgo MP (2010). Obesity and shift work: chronobiological aspects. Nutr Res Rev 23, 155-168.

Archer SN, Laing EE, Moller-Levet CS, van der Veen DR, Bucca G, Lazar AS, Santhi N, Slak A, Kabiljo R, von Schantz M, Smith CP \& Dijk DJ (2014). Mistimed sleep disrupts circadian regulation of the human transcriptome. Proc Natl Acad Sci U S A 111, E682-691.

Bass J (2012). Circadian topology of metabolism. Nature 491, 348-356.

Buhr ED \& Takahashi JS (2013). Molecular components of the Mammalian circadian clock. Handb Exp Pharmacol, 3-27.

Damiola F, Le Minh N, Preitner N, Kornmann B, Fleury-Olela F \& Schibler U (2000). Restricted feeding uncouples circadian oscillators in peripheral tissues from the central pacemaker in the suprachiasmatic nucleus. Genes Dev 14, 2950-2961.

Dyar KA, Ciciliot S, Wright LE, Bienso RS, Tagliazucchi GM, Patel VR, Forcato M, Paz MI, Gudiksen A, Solagna F, Albiero M, Moretti I, Eckel-Mahan KL, Baldi P, Sassone-Corsi P, Rizzuto R, Bicciato S, Pilegaard H, Blaauw B \& Schiaffino S (2014). Muscle insulin sensitivity and glucose metabolism are controlled by the intrinsic muscle clock. Mol Metab 3, 29-41.

Eckel-Mahan KL, Patel VR, de Mateo S, Orozco-Solis R, Ceglia NJ, Sahar S, Dilag-Penilla SA, Dyar KA, Baldi P \& Sassone-Corsi P (2013). Reprogramming of the circadian clock by nutritional challenge. Cell 155, 1464-1478.

Garaulet M, Gomez-Abellan P, Alburquerque-Bejar JJ, Lee YC, Ordovas JM \& Scheer FA (2013). Timing of food intake predicts weight loss effectiveness. Int J Obes (Lond) 37, 604-611.

Hatori M, Vollmers C, Zarrinpar A, DiTacchio L, Bushong EA, Gill S, Leblanc M, Chaix A, Joens M, Fitzpatrick JA, Ellisman MH \& Panda S (2012). Time-restricted feeding without reducing caloric intake prevents metabolic diseases in mice fed a high-fat diet. Cell Metab 15, 848860 .

Johnston JD (2012). Adipose circadian rhythms: translating cellular and animal studies to human physiology. Mol Cell Endocrinol 349, 45-50. 
295

296

297

298

299

300

301

302

303

304

305

306

307

308

309

310

311

312

313

314

315

316

317

318

319

320

321

322

323

324

Johnston JD (2014). Physiological responses to food intake throughout the day. Nutr Res Rev, 1-12.

Kohsaka A, Laposky AD, Ramsey KM, Estrada C, Joshu C, Kobayashi Y, Turek FW \& Bass J (2007). High-fat diet disrupts behavioral and molecular circadian rhythms in mice. Cell Metab 6, 414421.

Lamia KA, Storch KF \& Weitz CJ (2008). Physiological significance of a peripheral tissue circadian clock. Proc Natl Acad Sci U S A 105, 15172-15177.

Mantele S, Otway DT, Middleton B, Bretschneider S, Wright J, Robertson MD, Skene DJ \& Johnston JD (2012). Daily rhythms of plasma melatonin, but not plasma leptin or leptin mRNA, vary between lean, obese and type 2 diabetic men. PLoS One 7, e37123.

Marcheva B, Ramsey KM, Buhr ED, Kobayashi Y, Su H, Ko CH, Ivanova G, Omura C, Mo S, Vitaterna MH, Lopez JP, Philipson LH, Bradfield CA, Crosby SD, JeBailey L, Wang X, Takahashi JS \& Bass $J$ (2010). Disruption of the clock components CLOCK and BMAL1 leads to hypoinsulinaemia and diabetes. Nature 466, 627-631.

Mistlberger RE (2009). Food-anticipatory circadian rhythms: concepts and methods. Eur J Neurosci 30, 1718-1729.

Mohawk JA, Green CB \& Takahashi JS (2012). Central and peripheral circadian clocks in mammals. Annu Rev Neurosci 35, 445-462.

Morgan L, Hampton S, Gibbs M \& Arendt J (2003). Circadian aspects of postprandial metabolism. Chronobiol Int 20, 795-808.

Otway DT, Frost G \& Johnston JD (2009). Circadian rhythmicity in murine pre-adipocyte and adipocyte cells. Chronobiol Int 26, 1340-1354.

Otway DT, Mantele S, Bretschneider S, Wright J, Trayhurn P, Skene DJ, Robertson MD \& Johnston JD (2011). Rhythmic diurnal gene expression in human adipose tissue from individuals who are lean, overweight, and type 2 diabetic. Diabetes 60, 1577-1581.

Paschos GK, Ibrahim S, Song WL, Kunieda T, Grant G, Reyes TM, Bradfield CA, Vaughan CH, Eiden M, Masoodi M, Griffin JL, Wang F, Lawson JA \& Fitzgerald GA (2012). Obesity in mice with adipocyte-specific deletion of clock component Arntl. Nat Med 18, 1768-1777.

Rudic RD, McNamara P, Curtis AM, Boston RC, Panda S, Hogenesch JB \& Fitzgerald GA (2004). BMAL1 and CLOCK, two essential components of the circadian clock, are involved in glucose homeostasis. PLoS Biol 2, e377. 
338

339

340

341

342

343

344

345

346

347

348
Scott EM, Carter AM \& Grant PJ (2008). Association between polymorphisms in the Clock gene, obesity and the metabolic syndrome in man. Int J Obes (Lond) 32, 658-662.

Shea SA, Hilton MF, Orlova C, Ayers RT \& Mantzoros CS (2005). Independent circadian and sleep/wake regulation of adipokines and glucose in humans. J Clin Endocrinol Metab 90, 2537-2544.

Sinha MK, Ohannesian JP, Heiman ML, Kriauciunas A, Stephens TW, Magosin S, Marco C \& Caro JF (1996). Nocturnal rise of leptin in lean, obese, and non-insulin-dependent diabetes mellitus subjects. J Clin Invest 97, 1344-1347.

Storch KF \& Weitz CJ (2009). Daily rhythms of food-anticipatory behavioral activity do not require the known circadian clock. Proc Natl Acad Sci U S A 106, 6808-6813.

Turek FW, Joshu C, Kohsaka A, Lin E, Ivanova G, McDearmon E, Laposky A, Losee-Olson S, Easton A, Jensen DR, Eckel RH, Takahashi JS \& Bass J (2005). Obesity and metabolic syndrome in circadian Clock mutant mice. Science 308, 1043-1045.

Van Cauter E, Polonsky KS \& Scheen AJ (1997). Roles of circadian rhythmicity and sleep in human glucose regulation. Endocr Rev 18, 716-738.

Woon PY, Kaisaki PJ, Braganca J, Bihoreau MT, Levy JC, Farrall M \& Gauguier D (2007). Aryl hydrocarbon receptor nuclear translocator-like (BMAL1) is associated with susceptibility to hypertension and type 2 diabetes. Proc Natl Acad Sci U S A 104, 14412-14417. 